\title{
Nanoparticle-Mediated Drug Delivery System for Pulmonary Arterial Hypertension
}

\author{
Kazufumi Nakamura ${ }^{1, *}$, Hiromi Matsubara ${ }^{2}$, Satoshi Akagi ${ }^{1}$, Toshihiro Sarashina ${ }^{1}$, \\ Kentaro Ejiri ${ }^{1}$, Norifumi Kawakita ${ }^{1}$, Masashi Yoshida ${ }^{1}$, Toru Miyoshi ${ }^{1}$, Atsuyuki Watanabe ${ }^{1}$, \\ Nobuhiro Nishii ${ }^{1}$ and Hiroshi Ito ${ }^{1}$ \\ 1 Department of Cardiovascular Medicine, Okayama University Graduate School of Medicine, Dentistry and \\ Pharmaceutical Sciences, 2-5-1 Shikata-cho, Kita-ku, Okayama 700-8558, Japan; \\ akagi-s@cc.okayama-u.ac.jp (S.A.); sarashina.toshihiro@gmail.com (T.S.); eziken82@gmail.com (K.E.); \\ rm3ta6@bma.biglobe.ne.jp (N.K.); masashiyoshid@gmail.com (M.Y.); miyoshit@cc.okayama-u.ac.jp (T.M.); \\ atsunao0422@gmail.com (A.W.); nnnnishii2001@gmail.com (N.N.); itomd@md.okayama-u.ac.jp (H.I.) \\ 2 Division of Cardiology, National Hospital Organization Okayama Medical Center, Okayama 701-1192, \\ Japan; matsubara.hiromi@gmail.com \\ * Correspondence: ichibun@cc.okayama-u.ac.jp; Tel.: +81-86-235-7351; Fax: +81-86-235-7353 \\ Academic Editor: Jane A. Leopold \\ Received: 24 January 2017; Accepted: 22 April 2017; Published: 29 April 2017
}

\begin{abstract}
Nanoparticles have been used as a novel drug delivery system. Drug-incorporated nanoparticles for local delivery might optimize the efficacy and minimize the side effects of drugs. The efficacy and safety of intratracheal administration of prostacyclin analog (beraprost) -incorporated nanoparticles and imatinib (a PDGF-receptor tyrosine kinase inhibitor) -incorporated nanoparticles in Sugen-hypoxia-normoxia or monocrotaline rat models of pulmonary arterial hypertension (PAH) and in human PAH-pulmonary arterial smooth muscle cells have been reported. The use of inhaled drug-incorporated nanoparticles might be a novel approach for the treatment of PAH.
\end{abstract}

Keywords: pulmonary arterial hypertension; prostacyclin; nanoparticle; drug delivery system

\section{Introduction}

Pulmonary arterial hypertension $(\mathrm{PAH})$ is a life-threatening and progressive disease characterized by progressively elevated pulmonary vascular resistance (PVR) and pulmonary artery pressure. Increased PVR is induced by pulmonary vasoconstriction, vascular remodeling by intimal and medial hypertrophy, and thrombosis [1-3]. Sustained elevation of pulmonary vascular resistance causes severe right ventricular (RV) hypertrophy and failure, leading to a poor prognosis. PAH-targeted drugs, including prostacyclin (prostaglandin $\mathrm{I}_{2}$ ), endothelin receptor antagonists (ERAs), phosphodiesterase type-5 inhibitors (PDE-5i) and a soluble guanylate cyclase stimulator, have become available in the past two decades, and treatment with these vasodilators has been effective [4-8]. However, their full therapeutic abilities are reduced by medication non-compliance and side effects, and PAH is still a fatal disorder in many patients. To solve these problems, several novel therapeutic strategies for PAH, including nanoparticle-mediated drug delivery systems, (nano-DDS) are proposed.

\section{Prostacyclin Therapy for PAH}

The release of endogenous prostacyclin (prostaglandin $\mathrm{I}_{2}$ ) is depressed in patients with PAH. Prostacyclin replacement therapy by infusion of epoprostenol sodium, a prostacyclin (prostaglandin $\mathrm{I}_{2}$ ), is one of the best treatments available for PAH. High-dose epoprostenol therapy ( $>40 \mathrm{ng} / \mathrm{kg} / \mathrm{min})$ resulted in marked hemodynamic improvement in patients with idiopathic PAH (IPAH) $[4,9]$. Compared with the baseline state, high-dose epoprostenol therapy reduced mean pulmonary arterial 
pressure (mPAP) by 30\% and PVR by $68 \%$. We have also reported that high-dose epoprostenol has a pro-apoptotic effect on pulmonary artery smooth muscle cells (PASMCs) of patients with PAH via the IP receptor [10].

However, epoprostenol therapy causes several adverse events and complications such as headaches, hypotension and catheter-related infections. Chronic infusion of epoprostenol is performed using a small, portable infusion pump through an indwelling central venous catheter. The most serious complication is catheter-related infections. The catheter infection rate was 0.26 per 1000 catheter days in PAH patients treated with epoprostenol [11]. Systemic administration of prostacyclin can induce headaches, flushing and sometimes severe hypotension at the start of prostacyclin therapy. These problems would be solved if an alternative system that targeted the delivery of the prostacyclin to the pulmonary vasculature without using a central venous catheter is developed.

\section{Imatinib for the Treatment of PAH}

Remodeling of the pulmonary artery by an inappropriate increase of PASMCs is problematic in the treatment of PAH. Effective treatment that achieves reverse remodeling is required. This will require anti-proliferative and pro-apoptotic agents for PASMCs.

We have reported that platelet-derived growth factor (PDGF)-BB stimulation caused a higher growth rate of cultured PASMCs from patients with IPAH than that of control cells [12,13]. Imatinib is a PDGF-receptor tyrosine kinase inhibitor, and is a drug used to treat certain types of cancer such as chronic myelogenous leukemia and gastrointestinal stromal tumors. Schermuly et al. reported that imatinib reverses pulmonary vascular remodeling and cor pulmonale in rats with monocrotaline-induced pulmonary hypertension $(\mathrm{PH})$, as well as in mice with chronic hypoxia-induced $\mathrm{PH}$ [14]. Imatinib has anti-proliferative and pro-apoptotic effects on IPAH-PASMCs stimulated with (PDGF)-BB [15].

Clinical improvement and hemodynamic improvement have been reported in some patients with PAH who were treated with imatinib [16,17]. However, a randomized, double-blind, placebo-controlled trial showed that imatinib improved exercise capacity and hemodynamics in patients with severe PAH, but that serious adverse events and drug discontinuations were common with this treatment [18]. Since systemic administration of imatinib causes serious adverse events, the development of a new route of administration is required.

\section{Nano-DDS}

Nanoparticles (NPs) have been used as a novel delivery system for the transport of drugs to target organs [19-21]. NPs are taken up by the target organ because of their small size, permeability, and retention effect. Drug release from NPs is controlled according to the NP composition. Thus, drug-incorporated NPs for local delivery might optimize the efficacy and minimize the side effects of drugs. Liposomes and polymers have been tested as nano-DDSs in basic and clinical studies.

As for the treatment of PAH, treatment with vasodilators such as prostacyclin, ERAs and PDE-5i has been effective [4-8], though PAH is still a fatal disorder in many patients. Several novel therapeutic strategies for PAH including nano-DDS are proposed. Systemic administration of prostacyclin or imatinib causes several adverse events and complications. Nano-DDSs targeting the lung would optimize the efficacy and minimize the side effects of drugs. Pitavastatin [22], nuclear factor kappaB decoy [23], imatinib [24], prostacyclin analog [25,26], fasudil [27], and antimiRNA-145-incorporated NPs [28] have been reported to be effective in animal models of PAH (Table 1). In this review, we summarize the results of these studies. All of the data in these studies were obtained in rat models of $\mathrm{PAH}$ and have not yet been translated to human trials. The efficacy and safety of nano-DDSs for PAH in humans are unknown. Further studies are needed to clarify these points. 
Table 1. Nanoparticle-mediated drug delivery systems for pulmonary arterial hypertension treatment.

\begin{tabular}{|c|c|c|c|c|}
\hline Drug & Delivery System & Animal Model & $\begin{array}{c}\text { Route of } \\
\text { Administration }\end{array}$ & References \\
\hline Pitavastatin & Polymer (PLGA) & MCT-induced rat model & Intratracheal & [22] \\
\hline NF-kB decoy & $\begin{array}{c}\text { Polymer } \\
\text { (PEG-PLGA) }\end{array}$ & MCT-induced rat model & Intratracheal & [23] \\
\hline Imatinib & Polymer (PLGA) & MCT-induced rat model & Intratracheal & [24] \\
\hline Beraprost & $\begin{array}{l}\text { Polymer (PLA and } \\
\text { PEG-PLA) }\end{array}$ & MCT-induced rat model & Intravenous & [25] \\
\hline \multirow{2}{*}{ Beraprost } & \multirow{2}{*}{ Polymer (PLGA) } & MCT-induced rat model & \multirow{2}{*}{ Intratracheal } & \multirow{2}{*}{ [26] } \\
\hline & & Sugen/hypoxia rat model & & \\
\hline Fasudil & Liposome & MCT-induced rat model & Inhalation & [27] \\
\hline AntimiRNA-145 & Liposome & Sugen/hypoxia rat model & Intravenous & [28] \\
\hline
\end{tabular}

Note: NF-kB, nuclear factor kappaB; PLGA, polylactide-glycolide; PEG-PLGA, poly-(ethyleneglycol)-block-PLGA; MCT, monocrotaline; PLA, poly(lactide) homoplymer; PEG-PLA, poly-(ethyleneglycol)-PLA.

\subsection{Prostacyclin Analog-Incorporated NPs}

We investigated the efficacy and safety of intratracheal administration of NPs incorporated with beraprost, a prostacyclin analog (beraprost-NPs) in Sugen-hypoxia-normoxia and monocrotaline (MCT) rat models of PAH (Figure 1) [26]. Nanoparticles of polylactide-glycolide (PLGA), a polymer, encapsulated with beraprost were used in the study. After a single administration, beraprost-NPs significantly decreased right ventricular pressure, right ventricular hypertrophy, and pulmonary artery muscularization in both rat models. Beraprost-NPs significantly improved the survival rate in the MCT rat model. No infiltration of inflammatory cells, hemorrhage, or fibrosis was found in the liver, kidney, spleen or heart after the administration of beraprost-NPs.

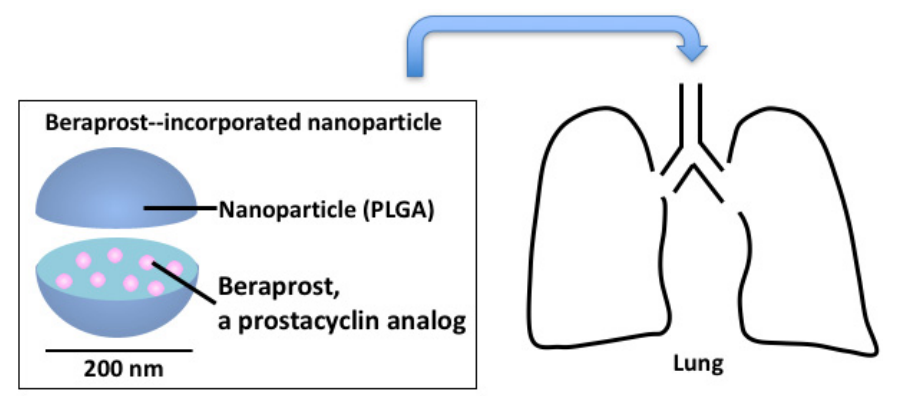

Figure 1. Prostacyclin analog-incorporated nanoparticles for treatment of pulmonary arterial hypertension.

Ishihara et al. also reported that the intravenous administration of beraprost encapsulated into nanoparticles prepared from a poly(lactide) homopolymer (PLA) and monomethoxy poly(ethyleneglycol)-poly(lactide) block copolymer protected against MCT-induced pulmonary arterial remodeling and right ventricular hypertrophy, and that once per week intravenous administration of beraprost-NPs also had an ameliorative effect on hypoxia-induced pulmonary arterial remodeling and right ventricular hypertrophy [25].

\subsection{Imatinib-Incorporated NPs}

We examined the efficacy of imatinib-incorporated NPs (Ima-NPs) in the MCT rat model of PAH and in human PAH-PASMCs [24]. A single intratracheal administration of Ima-NPs suppressed the development of MCT-induced PAH in rats. Ima-NPs had sustained antiproliferative effects on human PAH-PASMCs. 


\subsection{Pitavastatin-Incorporated NPS}

Chen et al. reported that intratracheal treatment with pitavastatin-incorporated NP, but not with pitavastatin, attenuated the development of MCT-induced PAH in rats and was associated with a reduction of inflammation and pulmonary arterial remodeling [22]. The fluorescein isothiocyanate (FITC) signals were detected in small bronchial tracts, alveolar macrophages, and small pulmonary arteries (PAs) for up to 14 days after a single instillation of FITC-encapsulated PLGA NP. Furthermore, treatment with pitavastatin-NP three weeks after MCT injection induced the regression of PAH and improved the survival rate. These results suggest potential clinical significance for developing a new treatment for PAH.

\subsection{Fasudil-Incorporated NPS}

Pulmonary hypertension is associated with hypoxic exposure, endothelial dysfunction, and PASMC hypercontraction and proliferation for which Rho-kinase seems to be substantially involved [29]. Long-term treatment with fasudil, a Rho-kinase inhibitor, suppresses the development of MCT-induced PAH in rats [30] and hypoxia-induced PAH in mice [31].

Gupta et al. reported that intratracheal instillation of liposomal fasudil reduced mPAP in MCT-induced PAH rats and that the effect continued for about $3 \mathrm{~h}$, suggesting that liposomal formulations produced pulmonary preferential vasodilation [27].

\subsection{Oligonucleotides-Incorporated NPS}

Decoy oligonucleotides are used as inhibitors of specific gene expression without any changes in the functions of other genes [32]. Kimura et al. reported that the activity of nuclear factor $k \mathrm{~B}$ (NF-kB), a transcription factor which regulates proinflammatory cytokines, increased in the MCT rat model of PAH, while intratracheal instillation of NF-kB decoy oligonucleotides-NPs (PEG-PLGA) attenuated the development of MCT-induced PAH in rats [23]. Moreover, treatment with NF-kB decoy NPs three weeks after MCT injection improved the survival rate as compared with vehicle administration.

RNA interference (RNAi) reduces the expression of pathological proteins. Currently, RNAi-based therapies exhibit the potential to be a novel therapeutic strategy in various diseases [33]. McLendon et al. reported that lipid nanoparticle delivery of an antisense oligonucleotide against microRNA-145 improved Sugen-hypoxia-induced PAH in rats [28].

\section{Summary and Clinical Perspective}

In this review, we summarized the properties of selected nano-DDSs and the results of preclinical studies using the nano-DDSs in animal models of PAH. Drug-incorporated nanoparticles for local delivery might optimize the efficacy and minimize the side effects of drugs.

A phase I investigator-initiated clinical trial to test the efficacy of PLGA nanoparticle-mediated delivery of pitavastatin (UMIN000014940) has been completed. Future clinical trials may prove the safety and efficacy of a nano-DDS for PAH.

Acknowledgments: This work was supported in part by the grants-in-aid for Scientific Research from the Ministry of Education, Culture, Sports, Science and Technology, Tokyo, Japan (Nakamura K) (15K09158)

Author Contributions: K.N., and H.M. designed this article, S.A., T.S., K.E., N.K., M.Y., T.M., A.W., N.N. contributed to literature review and I.H. is a supervisor.

Conflicts of Interest: Nakamura received lecture fees from Bayer Yakuhin, Ltd., Pfizer Japan Inc., Nippon Shinyaku Co., Ltd., Actelion Pharmaceuticals Japan Ltd., Novartis Pharma K.K. and GlaxoSmithKline K.K. Matsubara received lecture fees from Bayer Yakuhin, Ltd., Pfizer Japan Inc., Nippon Shinyaku Co., Ltd., Actelion Pharmaceuticals Japan Ltd. and GlaxoSmithKline K.K. Ito received research grants from Bayer Yakuhin, Ltd., Pfizer Japan Inc., Nippon Shinyaku Co., Ltd., and Actelion Pharmaceuticals Japan Ltd. and lecture fees from Bayer Yakuhin, Ltd.; Akagi, Sarashina, Ejiri, Kawakita, Yoshida, Miyoshi, Watanabe and Nishii have no conflict of interest associated with this research. 


\section{References}

1. Archer, S.; Rich, S. Primary pulmonary hypertension: A vascular biology and translational research "Work in progress". Circulation 2000, 102, 2781-2791. [CrossRef] [PubMed]

2. Miura, A.; Nakamura, K.; Kusano, K.F.; Matsubara, H.; Ogawa, A.; Akagi, S.; Oto, T.; Murakami, T.; Ohtsuka, A.; Yutani, C.; et al. Three-dimensional structure of pulmonary capillary vessels in patients with pulmonary hypertension. Circulation 2010, 121, 2151-2153. [CrossRef] [PubMed]

3. Jorge, E; Baptista, R.; Calisto, J.; Faria, H.; Monteiro, P.; Pan, M.; Pego, M. Optical coherence tomography of the pulmonary arteries: A systematic review. J. Cardiol. 2016, 67, 6-14. [CrossRef] [PubMed]

4. Akagi, S.; Nakamura, K.; Miyaji, K.; Ogawa, A.; Kusano, K.F.; Ito, H.; Matsubara, H. Marked hemodynamic improvements by high-dose epoprostenol therapy in patients with idiopathic pulmonary arterial hypertension. Circ. J. 2010, 74, 2200-2205. [CrossRef] [PubMed]

5. Saito, Y.; Nakamura, K.; Akagi, S.; Sarashina, T.; Ejiri, K.; Miura, A.; Ogawa, A.; Matsubara, H.; Ito, H. Epoprostenol sodium for treatment of pulmonary arterial hypertension. Vasc. Health Risk Manag. 2015, 11, 265-270. [PubMed]

6. Galie, N.; Corris, P.A.; Frost, A.; Girgis, R.E.; Granton, J.; Jing, Z.C.; Klepetko, W.; McGoon, M.D.; McLaughlin, V.V.; Preston, I.R.; et al. Updated treatment algorithm of pulmonary arterial hypertension. J. Am. Coll. Cardiol. 2013, 62, D60-D72. [CrossRef] [PubMed]

7. Galie, N.; Humbert, M.; Vachiery, J.L.; Gibbs, S.; Lang, I.; Torbicki, A.; Simonneau, G.; Peacock, A.; Vonk Noordegraaf, A.; Beghetti, M.; et al. 2015 ESC/ERS Guidelines for the diagnosis and treatment of pulmonary hypertension: The Joint Task Force for the Diagnosis and Treatment of Pulmonary Hypertension of the European Society of Cardiology (ESC) and the European Respiratory Society (ERS): Endorsed by: Association for European Paediatric and Congenital Cardiology (AEPC), International Society for Heart and Lung Transplantation (ISHLT). Eur. Heart J. 2016, 37, 67-119. [PubMed]

8. Matsubara, H.; Ogawa, A. Treatment of idiopathic/hereditary pulmonary arterial hypertension. J. Cardiol. 2014, 64, 243-249. [CrossRef] [PubMed]

9. Tokunaga, N.; Ogawa, A.; Ito, H.; Matsubara, H. Rapid and high-dose titration of epoprostenol improves pulmonary hemodynamics and clinical outcomes in patients with idiopathic and heritable pulmonary arterial hypertension. J. Cardiol. 2016, 68, 542-547. [CrossRef] [PubMed]

10. Akagi, S.; Nakamura, K.; Matsubara, H.; Kusano, K.F.; Kataoka, N.; Oto, T.; Miyaji, K.; Miura, A.; Ogawa, A.; Yoshida, M.; et al. Prostaglandin I2 induces apoptosis via upregulation of Fas ligand in pulmonary artery smooth muscle cells from patients with idiopathic pulmonary arterial hypertension. Int. J. Cardiol. 2013, 165, 499-505. [CrossRef] [PubMed]

11. Oudiz, R.J.; Widlitz, A.; Beckmann, X.J.; Camanga, D.; Alfie, J.; Brundage, B.H.; Barst, R.J. Micrococcus-associated central venous catheter infection in patients with pulmonary arterial hypertension. Chest 2004, 126, 90-94. [CrossRef] [PubMed]

12. Ogawa, A.; Nakamura, K.; Matsubara, H.; Fujio, H.; Ikeda, T.; Kobayashi, K.; Miyazaki, I.; Asanuma, M.; Miyaji, K.; Miura, D.; et al. Prednisolone inhibits proliferation of cultured pulmonary artery smooth muscle cells of patients with idiopathic pulmonary arterial hypertension. Circulation 2005, 112, 1806-1812. [CrossRef] [PubMed]

13. Fujio, H.; Nakamura, K.; Matsubara, H.; Kusano, K.F.; Miyaji, K.; Nagase, S.; Ikeda, T.; Ogawa, A.; Ohta-Ogo, K.; Miura, D.; et al. Carvedilol inhibits proliferation of cultured pulmonary artery smooth muscle cells of patients with idiopathic pulmonary arterial hypertension. J. Cardiovasc. Pharmacol. 2006, 47, 250-255. [CrossRef] [PubMed]

14. Schermuly, R.T.; Dony, E.; Ghofrani, H.A.; Pullamsetti, S.; Savai, R.; Roth, M.; Sydykov, A.; Lai, Y.J.; Weissmann, N.; Seeger, W.; et al. Reversal of experimental pulmonary hypertension by PDGF inhibition. J. Clin. Investig. 2005, 115, 2811-2821. [CrossRef] [PubMed]

15. Nakamura, K.; Akagi, S.; Ogawa, A.; Kusano, K.F.; Matsubara, H.; Miura, D.; Fuke, S.; Nishii, N.; Nagase, S.; Kohno, K.; et al. Pro-apoptotic effects of imatinib on PDGF-stimulated pulmonary artery smooth muscle cells from patients with idiopathic pulmonary arterial hypertension. Int. J. Cardiol. 2012, 159, 100-106. [CrossRef] [PubMed]

16. Ghofrani, H.A.; Seeger, W.; Grimminger, F. Imatinib for the treatment of pulmonary arterial hypertension. N. Engl. J. Med. 2005, 353, 1412-1413. [CrossRef] [PubMed] 
17. Hatano, M.; Yao, A.; Shiga, T.; Kinugawa, K.; Hirata, Y.; Nagai, R. Imatinib mesylate has the potential to exert its efficacy by down-regulating the plasma concentration of platelet-derived growth factor in patients with pulmonary arterial hypertension. Int. Heart J. 2010, 51, 272-276. [CrossRef] [PubMed]

18. Hoeper, M.M.; Barst, R.J.; Bourge, R.C.; Feldman, J.; Frost, A.E.; Galie, N.; Gomez-Sanchez, M.A.; Grimminger, F.; Grunig, E.; Hassoun, P.M.; et al. Imatinib mesylate as add-on therapy for pulmonary arterial hypertension: Results of the randomized IMPRES study. Circulation 2013, 127, 1128-1138. [CrossRef] [PubMed]

19. Kim, B.Y.; Rutka, J.T.; Chan, W.C. Nanomedicine. N. Engl. J. Med. 2010, 363, 2434-2443. [CrossRef] [PubMed]

20. Matoba, T.; Egashira, K. Nanoparticle-mediated drug delivery system for cardiovascular disease. Int. Heart J. 2014, 55, 281-286. [CrossRef] [PubMed]

21. Vaidya, B.; Gupta, V. Novel therapeutic approaches for pulmonary arterial hypertension: Unique molecular targets to site-specific drug delivery. J. Control. Release 2015, 211, 118-133. [CrossRef] [PubMed]

22. Chen, L.; Nakano, K.; Kimura, S.; Matoba, T.; Iwata, E.; Miyagawa, M.; Tsujimoto, H.; Nagaoka, K.; Kishimoto, J.; Sunagawa, K.; et al. Nanoparticle-mediated delivery of pitavastatin into lungs ameliorates the development and induces regression of monocrotaline-induced pulmonary artery hypertension. Hypertension 2011, 57, 343-350. [CrossRef] [PubMed]

23. Kimura, S.; Egashira, K.; Chen, L.; Nakano, K.; Iwata, E.; Miyagawa, M.; Tsujimoto, H.; Hara, K.; Morishita, R.; Sueishi, K.; et al. Nanoparticle-mediated delivery of nuclear factor kappaB decoy into lungs ameliorates monocrotaline-induced pulmonary arterial hypertension. Hypertension 2009, 53, 877-883. [CrossRef] [PubMed]

24. Akagi, S.; Nakamura, K.; Miura, D.; Saito, Y.; Matsubara, H.; Ogawa, A.; Matoba, T.; Egashira, K.; Ito, H. Delivery of imatinib-incorporated nanoparticles into lungs suppresses the development of monocrotaline-induced pulmonary arterial hypertension. Int. Heart J. 2015, 56, 354-359. [CrossRef] [PubMed]

25. Ishihara, T.; Hayashi, E.; Yamamoto, S.; Kobayashi, C.; Tamura, Y.; Sawazaki, R.; Tamur, F.; Tahara, K.; Kasahara, T.; Ishihara, T.; et al. Encapsulation of beraprost sodium in nanoparticles: Analysis of sustained release properties, targeting abilities and pharmacological activities in animal models of pulmonary arterial hypertension. J. Control. Release 2015, 197, 97-104. [CrossRef] [PubMed]

26. Akagi, S.; Nakamura, K.; Matsubara, H.; Kondo, M.; Miura, D.; Matoba, T.; Egashira, K.; Ito, H. Intratracheal Administration of Prostacyclin Analogue-incorporated Nanoparticles Ameliorates the Development of Monocrotaline and Sugen-Hypoxia-induced Pulmonary Arterial Hypertension. J. Cardiovasc. Pharmacol. 2016, 67, 290-298. [CrossRef] [PubMed]

27. Gupta, V.; Gupta, N.; Shaik, I.H.; Mehvar, R.; McMurtry, I.F.; Oka, M.; Nozik-Grayck, E.; Komatsu, M.; Ahsan, F. Liposomal fasudil, a rho-kinase inhibitor, for prolonged pulmonary preferential vasodilation in pulmonary arterial hypertension. J. Control. Release 2013, 167, 189-199. [CrossRef] [PubMed]

28. McLendon, J.M.; Joshi, S.R.; Sparks, J.; Matar, M.; Fewell, J.G.; Abe, K.; Oka, M.; McMurtry, I.F.; Gerthoffer, W.T. Lipid nanoparticle delivery of a microRNA-145 inhibitor improves experimental pulmonary hypertension. J. Control. Release 2015, 210, 67-75. [CrossRef] [PubMed]

29. Shimokawa, H.; Satoh, K. 2015 ATVB Plenary Lecture: Translational research on rho-kinase in cardiovascular medicine. Arterioscler. Thromb. Vasc. Biol 2015, 35, 1756-1769. [CrossRef] [PubMed]

30. Abe, K.; Shimokawa, H.; Morikawa, K.; Uwatoku, T.; Oi, K.; Matsumoto, Y.; Hattori, T.; Nakashima, Y.; Kaibuchi, K.; Sueishi, K.; et al. Long-term treatment with a Rho-kinase inhibitor improves monocrotaline-induced fatal pulmonary hypertension in rats. Circ. Res 2004, 94, 385-393. [CrossRef] [PubMed]

31. Abe, K.; Tawara, S.; Oi, K.; Hizume, T.; Uwatoku, T.; Fukumoto, Y.; Kaibuchi, K.; Shimokawa, H. Long-term inhibition of Rho-kinase ameliorates hypoxia-induced pulmonary hypertension in mice. J. Cardiovasc. Pharmacol. 2006, 48, 280-285. [CrossRef] [PubMed]

32. Ahmad, M.Z.; Akhter, S.; Mallik, N.; Anwar, M.; Tabassum, W.; Ahmad, F.J. Application of decoy oligonucleotides as novel therapeutic strategy: A contemporary overview. Curr. Drug Discov. Technol. 2013, 10, 71-84. [PubMed]

33. Davidson, B.L.; McCray, P.B., Jr. Current prospects for RNA interference-based therapies. Nat. Rev. Genet. 2011, 12, 329-340.

(C) 2017 by the authors. Licensee MDPI, Basel, Switzerland. This article is an open access article distributed under the terms and conditions of the Creative Commons Attribution (CC BY) license (http:/ / creativecommons.org/licenses/by/4.0/). 